\title{
BOUNDS ON COEFFICIENTS AND THIRD HANKEL DETERMINANT FOR A CLASS OF ANALYTIC FUNCTIONS RELATED WITH CERTAIN CONIC DOMAIN
}

\author{
Jugal K. PRAJAPAT AND RajBAla
}

Abstract. In this paper, we obtain upper bounds on initial coefficients and third Hankel determinant

$$
H_{3,1}(f)=\left|\begin{array}{lll}
a_{1} & a_{2} & a_{3} \\
a_{2} & a_{3} & a_{4} \\
a_{3} & a_{4} & a_{5}
\end{array}\right|
$$

of the coefficients of analytic function $f(z)=z+a_{2} z^{2}+a_{3} z^{3}+\cdots$, belonging to the class $\mathscr{S}^{*}(q)$ in the open unit disk $\mathbb{D}$, which satisfies the subordination condition that

$$
z f^{\prime}(z) / f(z) \prec q(z) \quad(z \in \mathbb{D}),
$$

where $q(z)=\sqrt{1+z^{2}}+z$. Several results are presented exhibiting improvement in earlier work.

Mathematics subject classification (2010): 30C45.

Keywords and phrases: Analytic functions, starlike functions, Fekete-Szegö functional, Hankel determinant, subordination.

\section{REFERENCES}

[1] Y. Abu Muhan, L. Li And S. Ponnusamy, Extremal problems on the class of convex functions of order -1/2, Arch. Math. (Basel) 103(6)(2014), 461-471.

[2] R. M. Ali, N. E. Cho, V. Ravichandran And S. S. Kumar, First order differential subordinations for functions associated with the lemniscate of Bernoulli, Taiwanese J. Math. 16(2012), $1017-1026$.

[3] D. Bansal, S. Maharana and J. K. Prajapat, Third order Hankel determinant for certain univalent functions, J. Korean Math. Soc. 52(6)(2015), 1139-1148.

[4] B. Bhowmik, S. Ponnus amy And K. J. Wirths, On the Fekete-Szegö problem for concave univalent functions, J. Math. Anal. Appl. 373(2)(2011), 432-438.

[5] D. G. CAntor, Power series with integral coefficients, Bull. Amer. Math. Soc. 69(1963), 362-366.

[6] P. L. Duren, Univalent Functions, Springer Verlag, New York Inc. 1983.

[7] I. EFRAIMIDIS, A generalization of Livingston's coefficient inequalities for functions with positive real part, J. Math. Anal. Appl. 435(2016), 369-379.

[8] W. K. Hayman, On the second Hankel determinant of mean univalent functions, Proc. Lond. Math. Soc. 18(3)(1968), 77-94.

[9] F. R. KEOGH AND E. P. MERKES, A coefficients inequalities for certain classes of analytic functions, Proc. Amer. Math. Soc. 20(1969), 8-12.

[10] Y. C. Kim, S. Ponnus Amy AND T. Sugawa, Mapping properties of nonlinear integral operators and pre-Schwarzian derivatives, J. Math. Anal. Appl. 29(2) (2004), 433-447.

[11] S. K. LeE, V. RaVichandran And S. Subramanian, Bounds for the second Hankel determinant of certain univalent functions, J. Inequal. Appl. 2013(2013), Article 281, 17pp.

[12] R. J. LiBRA AND E. J. ZŁOTKIEWICZ, Early coefficients of the inverse of a regular convex function, Proc. Amer. Math. Soc. 85(2)(1982), 225-230. 
[13] L. Li And S. Ponnusamy, On the generalized Zalcman functional $\lambda a_{n}^{2}-22 n-1$ in the close-toconvex family, Proc. Amer. Math. Soc. 145(2017), 833-846.

[14] W. MA AND D. Minda, A unified treatment of some special classes of univalent functions, Proceedings of the Conference on complex Analysis (Tianjin, 1992), 157-169, Conf. Proc. Lecture Notes Anal I, International Press. Cambridge, MA 1994.

[15] A. K. Mishra, J. K. Prajapat and S. Maharana, Bounds on Hankel determinant for starlike and convex functions with respect to symmetric points, Cogent Math. Stat. 3(2016), 1160557.

[16] C. POMmerenke, On the coefficients and Hankel determinant of univalent functions, J. Lond. Math. Soc. 44(1966), 111-122.

[17] S. Ponnusamy, Differential subordination and starlike functions, Complex Variables: Theory and Appl. 19(1992), 185-194.

[18] S. Ponnusamy, Differential subordination concerning starlike functions, Proc. Ind. Acad. Sci. (Math. Sci.) 104(1994), 397-411.

[19] J. K. Prajapat, D. Bansal, A. Singh and A. K. Mishra, Bounds on third Hankel determinant for close-to-convex functions, Acta Univ. Sapientiae Math. 7(2)(2015), 210-219.

[20] J. K. Prajapat, S. Maharana and Deepak Bansal, Bounds on third Hankel Determinant for certain classes of analytic functions, Stud. Univ. Babes-Bolyai Math. 62(2)(2017), 183-195.

[21] R. K. RAINA AND J. SOKOŁ, On coefficient estimates for a certain class of starlike functions, Hacet. J. Math. Stat. 44(6)(2015), 1427-1433.

[22] J. SOKOŁ AND J. STANKIEWICZ, Radius of convexity of some subclasses of strongly starlike functions, Zeszyty Nauk. Politech. Rzeszowskiej Mat. 19(1996), 101-105.

[23] P. ZAPRAwA, Third Hankel determinants for subclasses of Univalent functions, Mediterr. J. Math. 14(19)(2017), 1-10. 